Revista Destaques Acadêmicos, Lajeado, v. 12, n. 3, 2020. ISSN 2176-3070

DOI: http://dx.doi.org/10.22410/issn.2176-3070.v12i3a2020.2701

http://www.univates.br/revistas

\title{
ANTICORPOS IRREGULARES ANTI-ERITROCITÁRIOS EM DOADORES DE SANGUE
}

\author{
Adna dos Santos Caldas ${ }^{1}$, Ingrid dos Santos Lamarão', \\ Rayeli Thaisse Pinheiro da Silva ${ }^{1}$, Tamiris Barata Leal ${ }^{1}$, Laine Celestino Pinto ${ }^{2}$, \\ Renata Bezerra Hermes de Castro $^{2}$, Sylvia de Fátima dos Santos Guerra ${ }^{2}$
}

Resumo: A prática transfusional é a transferência de componentes sanguíneos do doador para o receptor, ela é necessária em casos de cirurgias, traumatismos, doenças hematológicas como a anemia falciforme e em pessoas que sofreram grande perda sanguínea. O contato com agentes estranhos ou não próprios, como antígenos eritrocitários, induz o organismo a desencadear uma resposta imunológica, no qual produz anticorpos por plasmócitos, este fenômeno é conhecido como aloimunização que é caraterizado pela produção de anticorpos anti-eritrocitários irregulares. Ao longo dos anos foram descobertos mais de 36 grupos sanguíneos e diversos fenótipos de antígenos eritrocitários. O presente trabalho teve por objetivo realizar uma revisão sistemática descritiva da literatura afim de pesquisar a frequência dos anticorpos irregulares anti-eritrocitários em doadores de sangue. Foram encontrados 294 artigos, dos quais 290 foram da base de dados Pubmed, 02 da Scielo e 02 do Lilacs. Destes, 06 foram selecionados para o estudo e os demais (288), excluídos por não obedecerem aos critérios de inclusão. Os anticorpos mais frequentes foram Anti-M, Anti-Le ${ }^{\mathrm{a}}$, Anti-Le ${ }^{\mathrm{b}}$, Anti-N e Anti-P1 respectivamente, identificados com diferentes métodos imunohematológicos nos países da Índia, Lao, Tailândia, e Noruega, sendo mais prevalentes em homens, sendo que em alguns estudos foram mais frequentes em mulheres e outros em homens. Portanto é necessário a pesquisa de anticorpos irregulares em doadores de sangue para prevenir reações hemolíticas e doença hemolítica do recém-nascido (DHRN).

Palavras-chave: Aloimunização. Aloanticorpo. Doadores de sangue.

\section{INTRODUÇÃO}

A prática transfusional é a transferência de componentes sanguíneos do doador para o receptor, ela é necessária em casos de cirurgias, traumatismos, doenças hematológicas como a anemia falciforme e em pessoas que sofreram

1 Graduandas em Biomedicina, Faculdade Metropolitana da Amazônia, Belém, PA.

2 Docentes de Biomedicina, Faculdade Metropolitana da Amazônia, Belém, PA. 
grande perda sanguínea. A aloimunização é uma das possíveis reações transfusionais, sendo necessário o conhecimento de fenótipos eritrocitários em doadores de sangue (BAIOCHI; NARDOZZA, 2009).

$\mathrm{O}$ contato com agentes estranhos ou não próprios, como antígenos eritrocitários, induz o organismo a desencadear uma resposta imunológica, no qual produz anticorpos por plasmócitos. Esse fenômeno é conhecido como aloimunização, que é caraterizado pela produção de anticorpos antieritrocitários irregulares que emergem contra os eritrócitos que foram transfundidos em indivíduos hemocompetentes. Eles são classicamente, denominados aloanticorpos, pois sua presença não é esperada, diferenciando-o dos anticorpos regulares, como o anti-A e o anti-B (AGUIAR, 2013).

O maior índice de anticorpos anti-eritrocitários é no sexo feminino com faixa etária entre 18 e 60 anos, e com maior frequência em mulheres variando entre 16 e 30 anos. Essa alta taxa de aloimunização em mulheres pode ser decorrente de fatores gestacionais e politransfusões (AGUIAR, 2013; LOKS et al., 2019).

A busca em conhecer cada vez mais as características dos eritrócitos, levou a descoberta, até o momento, de 38 grupos sanguíneos e diversos fenótipos de antígenos eritrocitários. No entanto, com o processo de aloimunização, tornouse necessário, também, conhecer a capacidade imunogênica desses antígenos, ou seja, de estimular a produção de anticorpos irregulares anti-eritrocitários, com propósito de entender como isso afetaria a relação doador-receptor (HELMAN; CANÇADO; CRISTINA, 2011; INTERNATIONAL SOCIETY OF BLOOD TRANSFUSION, 2019; SILVA, 2016).

No início do século $\mathrm{XX}$, um dos trabalhos mais relevantes para a área médica foram os achados de antígenos eritrocitários. Por volta de 1900, desde que o sistema $\mathrm{ABO}$ foi descoberto, mais de 300 antígenos eritrocitários foram retratados na literatura, sendo classificados em sistemas, séries e coleções (INTERNATIONAL SOCIETY OF BLOOD TRANSFUSION, 2019; OLIVEIRA, 2016).

O sistema Rh foi descoberto 30 anos após o surgimento do sistema ABO, que apesar do seu importante papel na transfusão sanguínea, houveram ainda muitos casos de morte entre os transfundidos de mesmo grupo sanguíneo $\mathrm{ABO}$. Com o estudo das possíveis causas dessas complicações, foi identificado o antígeno D, primeiro antígeno do sistema Rh e o mais imunogênico do grupo, que está fortemente associado às complicações fatais. Os anticorpos antieritrocitários produzidos contra os antígenos Rh são, geralmente, IgG quentes (OLIVEIRA; BRAGA, 2015; SILVA, 2011).

Como descrito por Alves et al (2012), além do grupo Rh, os antígenos dos sistemas Kell (antígeno K), Kidd (antígenos Jk e Jka), Duffy (antígenos Fy e Fya) e MNS (antígenos S e s) também são capazes de induzir a produção de anticorpos irregulares, da classe IgG. Esses anticorpos, por sua vez, possuem 
alta importância transfusional, por serem responsáveis em causar reações hemolíticas graves nos pacientes. Os anticorpos mais significativos clinicamente

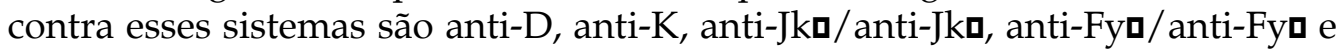
anti-S /anti-s (RODRIGUES, 2016).

Considerando que os hemocomponentes plasmáticos de doadores aloimunizados podem apresentar estes anticorpos, faz-se necessário a busca de anticorpos irregulares através do Teste de Antiglobulina (Coombs) indireto visando identificar o surgimento de anticorpos anti-eritrocitários no sangue do doador, afim de evitar reações pós-transfusionais no receptor.

Outros testes também podem ser usados na detecção de anticorpos irregulares como Aglutinação em Coluna (CAT), cartão em gel e entre outros. (BRASIL, 2014; CONGRESSO NACIONAL DE INICIAÇÃ̃O CIENTÍFICA, 2013).

O Anexo IV da Portaria de Consolidação de ${ }^{\circ} 5 / 2017$, que preconiza os critérios básicos para procedimentos hemoterápicos, deixa bem esclarecida a obrigatoriedade da triagem sanguínea pré-transfusional tal como a tipagem dos sistemas $\mathrm{ABO}$ e Rh, triagem de anticorpos, como a pesquisa de anticorpos irregulares anti-eritrocitários (PAI) em doadores e pacientes, e, testes de compatibilidade. No processo de triagem de anticorpos irregulares antieritrocitários devem ser utilizados metodologias que permitam a detecção de anticorpos de maior importância clínica (BRASIL, 2016).

O princípio do Teste de Antiglobulina Indireto (TAI) é a detecção de anticorpos anti-eritrocitários irregulares através do soro de Coombs que estimula uma interação antígeno-anticorpo e possui potencializadores de aglutinação de hemácias sensibilizadas com esses anticorpos irregulares. Anticorpos irregulares são mais em mulheres por desenvolver a Doença Hemolítica Perinatal (DHPN), por isso é relevante a realização do teste TAI para a prevenção da DHPN em doadores (BRASIL, 2014; ROSA, 2018; VIZZON, SILVA, 2015). Além do mais, indivíduos com anemias hemolíticas autoimunes ou induzidas por drogas, com reações hemolíticas transfusionais ou que realizaram transfusões múltiplas de sangue devem ser investigados, pois são possíveis portadores desses anticorpos e, portanto, devem realizar o TAI, afim de realizar transfusões de forma segura (GARG; SHARMA; SINGH, 2014; RODRIGUES, 2015). Assim, o presente trabalho tem por objetivo realizar uma revisão sistemática descritiva da literatura afim de pesquisar a frequência dos anticorpos irregulares anti-eritrocitários em doadores de sangue.

\section{MATERIAIS E MÉTODOS}

O presente estudo consiste em uma revisão sistemática descritiva da literatura de artigos científicos realizada no período de fevereiro a março de 2018 sobre anticorpos irregulares anti-eritrocitários em doadores de sangue. 
Para a elaboração deste artigo foram utilizadas as seguintes bases de dados: Google acadêmico, Literatura Latino-americana e do Caribe em Ciências da Saúde (Lilacs), National Library of Medicine (Pubmed) e Scielo. E nesta busca foi utilizado o descritor: "red cell alloantibodies blood donors".

Foram incluídos na pesquisa os artigos científicos primários, nos idiomas: inglês, espanhol e português, publicados entre os anos de 2008 a 2018, em domínio público, que apresentaram o conteúdo relacionado à frequência de anticorpos irregulares anti-eritrocitários em doadores de sangue.

Foram excluídos da pesquisa artigos que apresentaram incompatibilidade ao tema, artigos duplicados, artigos que não eram primários, estudos de caso, estudos com animais, monografias, artigos em outras línguas e artigos fora do período estipulado.

Ao final da investigação foram selecionados 6 artigos da base de dados PubMed para a apresentação e discussão dos resultados.

\section{RESULTADOS}

A busca realizada com o descritor "red cell alloantibodies blood donors", originou o total de 294 artigos encontrados, destes, 2 artigos na base de dados Lilacs, 290 artigos na base de dados PubMed e 2 artigos na base de dados Scielo, considerando critérios de inclusão e exclusão expostos no fluxograma 1. Após análise dos títulos e resumos dos artigos, foram selecionados 6 artigos na base de dados Pubmed para leitura na integra, sendo eles referentes aos anos 2012, 2013, 2014, 2017 e 2018 (Gráfico 1).

Gráfico 1. Quantidade de artigos incluídos segundo ano de publicação.

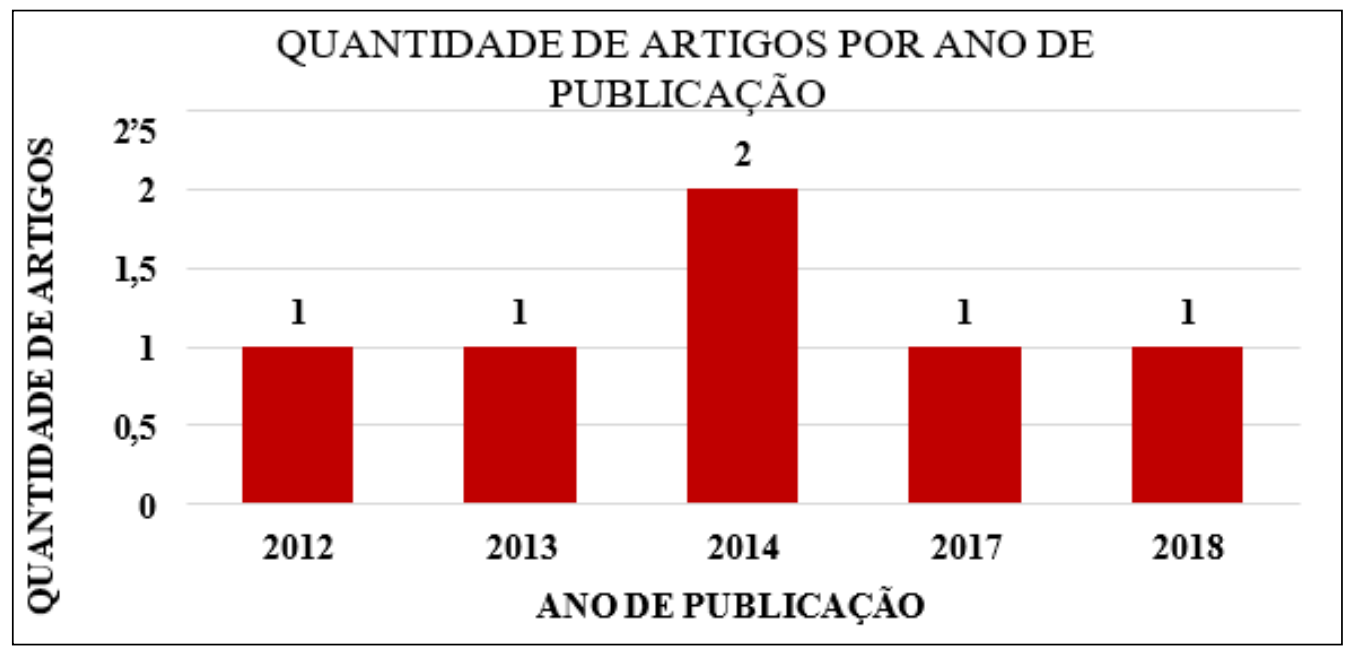

Fonte: Das autoras, 2018. 
Fluxograma 1: Quantidade de artigos encontrados com o descritor red cell alloantibodies blood donors, no banco de dados, Lilacs, Pubmed e Scielo.

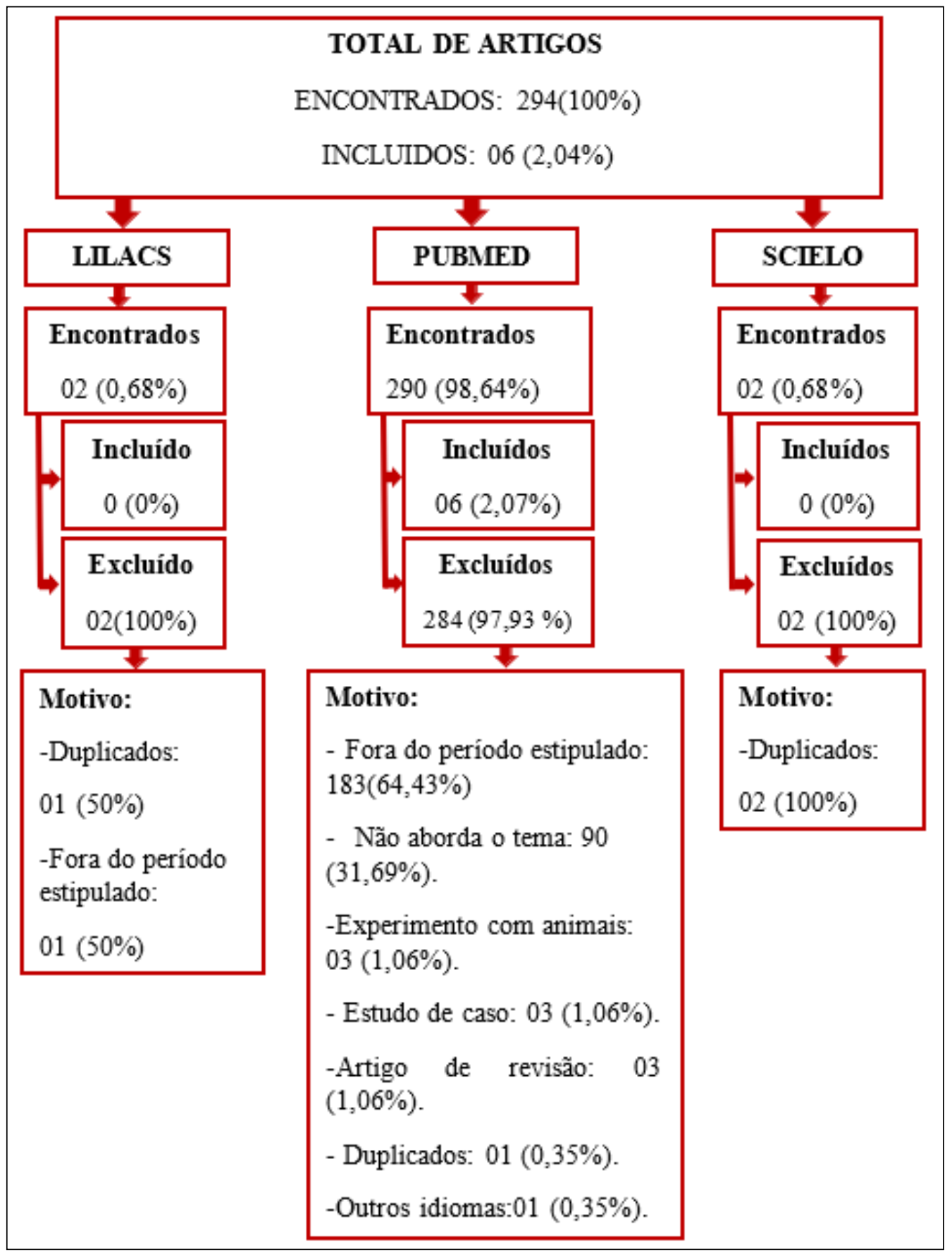

Fonte: Das autoras, 2018. 
De acordo com os artigos apresentados na tabela abaixo, mostram que destes, $03(50 \%)$ foram realizados em Delhi/Índia, 01 (16,67\%) em Vientiane/ Lao, $01(16,67 \%)$ no Sul da Tailândia e $01(16,67 \%)$ em Bergen/Noruega totalizando $06(100 \%)$ artigos abordados (Tabela 1).

Tabela 1: Dados referentes aos 6 artigos abordados sobre anticorpos irregulares em doadores de sangue.

\begin{tabular}{|c|c|c|c|c|c|c|c|}
\hline \multicolumn{2}{|c|}{ Autor/ ano } & $\begin{array}{c}\text { PAHUJA et al., } \\
2012\end{array}$ & $\begin{array}{l}\text { PROMWONG } \\
\text { et al., } 2013\end{array}$ & $\begin{array}{c}\text { GARG; } \\
\text { SHARMA; } \\
\text { SINGH, } \\
2014\end{array}$ & $\begin{array}{l}\text { KEOKHA } \\
\text { MPHOUI et } \\
\text { al., } 2014\end{array}$ & $\begin{array}{c}\text { ERIKSTEIN; } \\
\text { HAGEN; } \\
\text { HERVIG; } \\
2017 \\
\end{array}$ & $\begin{array}{l}\text { MAKROO et } \\
\text { al., } 2018\end{array}$ \\
\hline \multicolumn{2}{|c|}{ Local } & Delhi/ Índia & Sul da Tailândia & Delhi/ Índia & Vientiane/ Lao & $\begin{array}{l}\text { Bergen/ } \\
\text { Noruega }\end{array}$ & Delhi/ Índia \\
\hline \multirow{3}{*}{\multicolumn{2}{|c|}{ Período dos estudos }} & \multirow{3}{*}{$\begin{array}{c}\text { Mar de 2010ar } \\
\text { de } \\
2011\end{array}$} & \multirow{2}{*}{$\begin{array}{c}1^{\circ} \text { - Jan-dez de } \\
2006\end{array}$} & \multirow{3}{*}{$\begin{array}{c}\text { Set de } \\
2011 \text { - mai de } \\
2013\end{array}$} & $\begin{array}{c}1^{\circ} \text {-Set-nov de } \\
2010\end{array}$ & \multirow{3}{*}{$\begin{array}{l}\text { Jan-dez de } \\
2013\end{array}$} & \multirow{3}{*}{$\begin{array}{c}\text { Jan de } \\
2012-\text { dez de } \\
2015\end{array}$} \\
\hline & & & & & $\begin{array}{c}2^{\circ} \text {-Jan-fev de } \\
2011\end{array}$ & & \\
\hline & & & $\begin{array}{c}2^{\circ}-\text { Jan de } \\
2008-\text { dez de } \\
2009\end{array}$ & & $\begin{array}{c}3^{\circ} \text {-Jan-fev de } \\
2012\end{array}$ & & \\
\hline \multirow{2}{*}{\multicolumn{2}{|c|}{ Metodologia }} & \multirow{2}{*}{$\begin{array}{c}\text { Tecnologia de } \\
\text { aglutinação } \\
\text { em coluna. } \\
\text { (CAT) }\end{array}$} & $\begin{array}{c}\begin{array}{c}\text { Técnica de } \\
\text { tubos }\end{array} \\
\end{array}$ & \multirow{2}{*}{\begin{tabular}{|} 
Tecnologia de \\
aglutinação \\
em \\
coluna. \\
(CAT)
\end{tabular}} & \multirow{2}{*}{$\begin{array}{l}\text { Múltiplo teste } \\
\text { do tubo de } \\
\text { Antiglobulina. } \\
\text { (Coombs } \\
\text { indireto) }\end{array}$} & \multirow[b]{2}{*}{$\begin{array}{l}\text { Teste de } \\
\text { Coombs em } \\
\text { cartão. }\end{array}$} & \multirow{2}{*}{$\begin{array}{l}\text { Tecnologia de } \\
\text { aderência } \\
\text { de células } \\
\text { vermelhas de } \\
\text { fase sólida. } \\
\text { (SPRCA) }\end{array}$} \\
\hline & & & $\begin{array}{c}\text { Tecnologia de } \\
\text { aglutinação em } \\
\text { coluna. } \\
\text { (CAT) }\end{array}$ & & & & \\
\hline \multirow{3}{*}{ Amostra } & Total & 7.756 & \begin{tabular}{|l|}
$1^{\circ}-20.786$ \\
$2^{\circ}-49.229$ \\
\end{tabular} & 47.450 & 1.181 & 2.441 & 82.153 \\
\hline & Homens & $8,6 \%(7.648)$ & ------------- & $99,1 \%(47.065)$ & $\begin{array}{c}69,5 \% \\
(821)\end{array}$ & ------------ & $\begin{array}{l}92,83 \% \\
(81.193) \\
\end{array}$ \\
\hline & Mulheres & $\begin{array}{l}1,4 \% \\
(108)\end{array}$ & ------------ & $\begin{array}{c}385 \\
(0,9 \%)\end{array}$ & $\begin{array}{c}360 \\
(30,5 \%)\end{array}$ & & $\begin{array}{c}, 17 \% \\
(960)\end{array}$ \\
\hline \multirow{4}{*}{$\begin{array}{c}\text { Prevalência } \\
\text { de } \\
\text { aloanticorpos }\end{array}$} & & $0,04 \%$ & $\begin{array}{c}1^{\circ}-0,6 \% \\
(116 / 20.786)\end{array}$ & \multirow{2}{*}{$\begin{array}{c}0,09 \% \\
(46 / 47.450)\end{array}$} & \multirow{2}{*}{$\begin{array}{c}3,9 \% \\
(46 / 1.181)\end{array}$} & \multirow{2}{*}{$\begin{array}{c}0,12 \% \\
(3 / 2441)\end{array}$} & \multirow{2}{*}{$\begin{array}{c}0,09 \% \\
(76 / 82.153)\end{array}$} \\
\hline & Total & & $\begin{array}{c}2^{\circ}-0,13 \% \\
(65 / 49.229) \\
\end{array}$ & & & & \\
\hline & Homens & $100 \%(3 / 7.648)$ & ------------- & $\begin{array}{c}0,087 \% \\
(41 / 47.065)\end{array}$ & $\begin{array}{c}4,14 \% \\
(34 / 821)\end{array}$ & & $\begin{array}{c}0,077 \% \\
(63 / 81.193)\end{array}$ \\
\hline & Mulheres & $\begin{array}{c}0 \% \\
(0 / 108)\end{array}$ & - & $\begin{array}{c}1,29 \% \\
(5 / 385)\end{array}$ & $\begin{array}{c}3,33 \% \\
(12 / 360)\end{array}$ & & $\begin{array}{c}1,35 \% \\
(13 / 960)\end{array}$ \\
\hline \multicolumn{2}{|c|}{$\begin{array}{c}\text { Aloanticorpos mais } \\
\text { frequentes } \\
\text { encontrados nas amostras }\end{array}$} & $\begin{array}{c}\text { Amostras } 03 \\
\mathbf{( 0 , 0 4 \% )} \\
- \text { Anti-C } \\
66,67 \% \\
(2 / 3) \\
\text {-Anti-Le } \\
33,33 \% \\
(1 / 3)\end{array}$ & $\begin{array}{c}\text { Amostras } \\
\mathbf{1}^{\circ}-\mathbf{1 1 6} \\
\mathbf{( 0 , 6 \% )} \\
\text {-Anti-Le } \\
57,2 \% \\
\text {-Anti-Le } \\
29,0 \% \\
\text {-Anti-Mia } \\
\text { 7,0\% } \\
\text {-Anti-E } \\
3,5 \% \\
\text {-Anti-P }\end{array}$ & $\begin{array}{c}\text { Amostras } \\
\mathbf{4 6} \\
\mathbf{( 0 , 0 9 \% )} \\
- \text { Anti-N } \\
21,7 \% \\
(10 / 46) \\
- \text { Anti-M } \\
17,3 \% \\
(8 / 46) \\
- \text { Anti-D } \\
13,0 \% \\
(6 / 46)\end{array}$ & $\begin{array}{c}\text { Amostras } \\
\mathbf{4 6} \\
(3, \mathbf{9} \%) \\
\text {-Anti-P1 } \\
50 \% \\
(23 / 46) \\
- \text { Anti-Le }^{\mathrm{a}} \\
15,21 \% \\
(7 / 46) \\
- \text { Anti-Le }^{\mathrm{b}} \\
10,87 \% \\
(5 / 46)\end{array}$ & $\begin{array}{c}\text { Amostras } \\
\mathbf{0 3} \\
\mathbf{( 0 , 1 2 \% )} \\
\text { - Anti-M } \\
66,67 \% \\
(2 / 3) \\
- \text { Anti-c } \\
33,33 \% \\
(1 / 3)\end{array}$ & $\begin{array}{c}\text { Amostras } \\
\mathbf{7 6} \\
\mathbf{( 0 , 0 9 \% )} \\
- \text { Anti-M } \\
56,57 \% \\
(43 / 76) \\
\text {. Anti-D } \\
27,63 \% \\
(21 / 76) \\
. \text { Anti-N } \\
5,26 \% \\
(4 / 76)\end{array}$ \\
\hline
\end{tabular}




\begin{tabular}{|c|c|c|c|c|c|}
\hline & 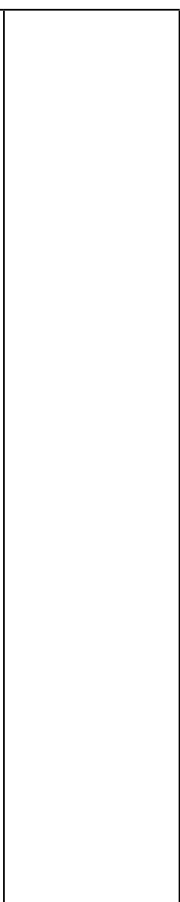 & 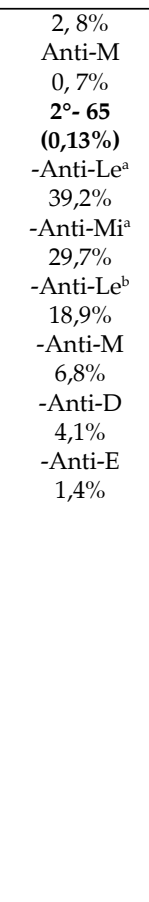 & $\begin{array}{c}- \text { Anti-Lea } \\
10,8 \% \\
(5 / 46) \\
-A n t i \mathrm{E}+\mathrm{K} \\
10,8 \% \\
(5 / 46) \\
- \text { Anti E } \\
6,5 \% \\
(3 / 46) \\
- \text { Anti-S } \\
6,5 \% \\
(3 / 46) \\
- \text { Anti-C } \\
2,1 \% \\
(1 / 46) \\
- \text { Anti c } \\
2,1 \% \\
(1 / 46) \\
\text { Anti } \\
\text { E+K+S } \\
2,1 \% \\
(1 / 46) \\
- \text { Anti Le a ab } \\
2,1 \% \\
(1 / 46) \\
\text { Anti K } \\
2,1 \% \\
(1 / 46) \\
\text { Anti Cw } \\
2,1 \% \\
(1 / 46)\end{array}$ & 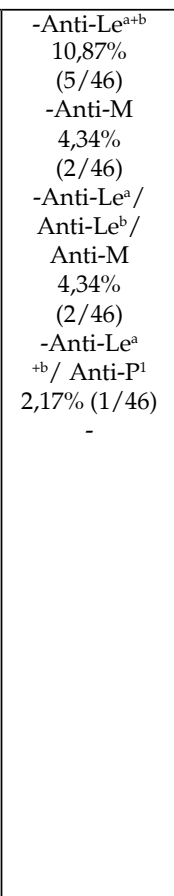 & $\begin{array}{c}\text {-Anti-JK } \\
2,63 \% \\
(2 / 76) \\
- \text { Anti-C } \\
2,63 \% \\
(2 / 76) \\
\text {-Anti-E } \\
2,63 \% \\
(2 / 76) \\
\text {-Anti-P1 } \\
1,31 \% \\
(1 / 76) \\
\text {-Anti- Le } \\
1,31 \% \\
(1 / 76)\end{array}$ \\
\hline
\end{tabular}

Fonte: Das autoras, 2018.

\section{DISCUSSÃO}

Os estudos abordados foram realizados na Índia, Lao, Tailândia e Noruega. E a frequência de anticorpos irregulares (aloanticorpos) foram identificados através dos métodos imuno-hematologicos das amostras de doadores de sangue.

Um dos estudos realizados em Delhi na Índia, no período de março de 2010 a março de 2011, com 7.756 doadores, sendo 98,6\% (7.648) amostras do sexo masculino e $1,4 \%$ (108) do sexo feminino. Através da técnica de rotina para a detecção de anticorpos eritrocitários no plasma/soro foi detectado $0,4 \%$ (3/7.756) doadores com amostra positiva para aloanticorpos, todos homens. Posteriormente foi realizado a identificação desses aloanticorpos, e 66,67\% (2/3) apresentou Anti-C, um destes tinha histórico de transfusão sanguínea quatro anos antecedente a doação de sangue. O terceiro com 33,33\% (1/3) foi para AntiLewis. A quantidade de amostras positivos foi baixa (apenas 3) por este motivo não foi possível estabelecer uma análise estatística do estudo. Vale ressaltar que a população amostral masculina foi dastricamente maior que a feminina, o que possivelmente explica essa baixa, considerando o papel da gestação do desenvolvimento de aloanticorpos em mulheres (PAHUJA et al., 2012). Outro estudo foi semelhante de Pahuja et al., 2012, no que diz respeito a quantidade de amostras positivas para aloanticorpos. Este, realizado na Noruega, utilizou 
o teste de Coombs em cartão, e identificou apenas $0,12 \%$ (3/2441) de amostras positivas para aloanticorpos, sendo que, Anti-M foi encontrado em $66,67 \%$ (2/3) e Anti-c, em 33,33\% (1/3) (ERIKSTEIN et al., 2017).

Ainda na Índia, outros dois estudos realizados por Garg, Sharma e Singh (2014) e Makroo et al (2018), mostraram maior taxa de aloimunização em mulheres (1,29 e 1,35\% respectivamente) que em homens $(0,087$ e $0,077 \%$, respectivamente). Esses dados são compatíveis com a literatura que apresenta claramente a associação entre a aloimunização e o sexo feminino, principalmente relacionado a gravidez. A prevalência de aloanticorpos do sistema MNS foi maior nos dois estudos, seguido pelo sistema Rh. No estudo de Garg, Sharma e Singh (2014), foi detectado 0,9\% (46/47.450) de amostras apresentando aloanticorpos, com maior frequência o anti- $\mathrm{N}$ correspondendo a $21,7 \%(10 / 46)$ e anti-M 17,3 (8/46), seguido pelo Anti-D, com frequência de $13,0 \%$ (6/46), este é o mais imunogênico por ser representante do sistema Rh, desta forma a triagem para detecção desse anticorpo em doadores torna-se importante para prevenir reações hemolíticas transfusionais.

No estudo de Makroo et al (2018), foi utilizado o método de tecnologia de aderência de células vermelhas de fase solida (SPRCA). As amostras de doadores apresentaram aloanticorpos em 0,09\% (76/82.153) dos indivíduos, sendo possível observar maior frequência do aloanticorpo Anti-M presente em $56,57 \%$ (43/76). O segundo mais frequente foi o aloanticorpo Anti-D presente em 27,63\% (21/76) das amostras de doadores, sendo o mais imunogênico dos antígenos e pode causar a doença hemolítica do feto e recém-nascido (DHDN) e reação transfusional. Além do mais, maioria das mulheres $(11 / 13)$ positivas para anti-D tinham histórico de parto cesárea e transfusão sanguínea e as outras duas relataram transfusão desconhecida, e cinco dos oito homens relataram transfusão sanguínea. Tomando como base que 13 mulheres e 63 homens participaram da pesquisa, a gestação e a transfusão conjunto pode ser a provável causa da alta taxa de anti-D em mulheres. O Anti-N esteve presente em 5,26\% (4/76) das amostras. Os aloanticorpos do sistema MNS, geralmente não reagem a $37^{\circ} \mathrm{C}$, porém, quando reagem a essa temperatura, podem ser clinicamente significativos com maior chance de causar reação transfusional hemolítica.

Promwong et al (2013), comparando duas técnicas para identificação de aloanticorpos em doadores de sangue do sul da Tailândia, observou que, na Técnica de Tubo Convencional, a prevalência de amostras com aloanticorpos foi de $0,6 \%(116 / 20.786)$ e na Tecnologia de Aglutinação em Coluna (CAT), a prevalência foi de $0,13 \%(65 / 49.229)$, sendo o anti-Le ${ }^{a}$, o mais frequente, em ambas as técnicas. $\mathrm{O}$ autor aborda que anti-Le (Sistema Lewis) e anti-Mi (Sistema Miltenberger) são comuns em tailandeses, chineses e taiwuaneses, mas não são tão frequentes em outras populações, principalmente caucasianos, portanto, levanta-se a hipótese de sua prevalência ter um caráter étnico. Apesar de não ter sido o mais frequente, o anti-Mi é clinicamente significativo nessa 
população por provocar casos de reações hemolíticas e doença hemolítica do recém-nascido, por isso é muito importante a triagem de aloanticorpos para detecção de anti-Mi nesses indivíduos. A variação da frequência de aloanticorpos entre as técnicas, pode ser explicada pela maior sensibilidade e qualidade do CAT em relação a técnica de tubos convencionais, e diferença de temperatura de incubação entre as técnicas. A técnica de tubos visa a detecção de anticorpos frios, e na CAT, o objetivo é a identificação de anticorpos quentes. Além do mais, esse foi o primeiro estudo da região, que foi utilizado a CAT.

Um trabalho feito em Lao, por Keokhamphoui1 et al (2014), identificou que 3,9\% (46/1.181) das amostras de doadores foram positivas para aloanticorpos, através do teste de Coombs indireto. E o aloanticorpo mais frequente foi o anti-P1 detectado em 50\% (23/46) das amostras, estes aloanticorpos, possivelmente, se desenvolveram de forma natural, considerando que, no país é comum o acometimento hepático por vermes que possui em sua superfície substancias semelhantes ao antígeno P1, como os Clonorchis sinensis e Opisthochis viverrini. O anticorpo Anti-Le apresentou 15,22\% (7/46), sendo o segundo mais frequente. Diferente do que ocorreu nas pesquisas de Garg, Sharma e Singh (2014) e Makroo et al (2018), os homens $(4,14 \%)$ foram mais prevalentes que mulheres $(3,33 \%)$, apesar de não ser declarada nenhuma justificativa que explique para esta ocorrência.

Pode-se verificar que dois estudos realizados na Índia apresentam informações semelhantes quanto a prevalência de doadores com positividade para aloanticorpos. Os autores definem que os métodos de triagem e as peculiaridades étnicas e populacionais podem estar diretamente relacionados com a taxa de aloimunização. Para sustentar tais justificativas, é apontado que a prevalência de doadores aloimunizados, é muito inferior a maioria dos estudos feitos, onde a incidência variou de $0,32 \%$ a $2,4 \%$ de doadores. No entanto, os resultados obtidos nestes estudos foram estatisticamente significativos (GARG; SHARMA; SINGH, 2014; MAKROO et al., 2018).

A partir dos dados descritos, percebe-se que a maior prevalência de doadores com aloanticorpos foi encontrado na pesquisa de Keokhamphoui et al (2014) (3,90\%), no entanto, a classe de anticorpo irregular mais frequente variou de acordo com a população estudada ou técnicas utilizadas.

Os resultados apresentados a partir de diferentes técnicas e regiões de pesquisa, mostram um conjunto variável de anticorpos irregulares. Anticorpos da classe IgG não conhecidos por causar tanto reações transfusionais como RHRN com maior ou menor frequência e intensidade. Anticorpos IgM, no entanto, como não atravessam a barreira placentária, geralmente não estão relacionados a casos de RHRN, mas são muito frequentes nas reações transfusionais. Além do mais, é válido entender que anticorpos podem apresentar reações significativas dependendo da temperatura em que reagem ou da etnia. A exemplo disso, anti-M pode não ser clinicamente importante quando reage a temperatura ambiente, mas tem alta relevância quando 
reage a $37{ }^{\circ} \mathrm{C}$. Da mesma forma anti-K é considerado mais prevalente em indivíduos caucasianos que em asiáticos por questões genéticas associadas, mas apresentam importância clínica em ambos os casos. Assim, atentar para os métodos ou técnicas viáveis para cada classe de aloanticorpos eritrocitários, desenvolver novas pesquisas baseadas em etnias, dentre outras categorias, é indispensável para se conhecer a amplitude epidemiológica e clínica desses anticorpos (MAKROO et al., 2018; PROWONG et al., 2013)

Também, fatores como o tamanho da população estudada, o equilíbrio quantitativo de homens e mulheres, predisposições genéticas a formação de aloanticorpos, além das limitações dos testes usados são possíveis pontos a serem levados em consideração para realização de uma pesquisa com tal importância. A necessidade de romper essas limitações é um desafio que deve ser confrontado, devido a aloimunização ser um fenômeno presente na população mundial e ainda assim, poucos estudos apresentam relatórios minimamente suficientes de triagem adequada para esse grupo de anticorpos (ERIKSTEIN; HAGEN; HERVING, 2018).

Ao se falar de limitações no campo da pesquisa de anticorpos irregulares, o uso de técnicas mais sensíveis e eficientes para esse fim devem ser incentivadas através de diretrizes mais concisas e rígidas afim de tornar o processo de identificação dos anticorpos irregulares mais precisa. Atualmente, técnicas para identificação de anticorpos como TAI são muito mais sensíveis que técnicas convencionais, o que proporciona maior segurança no momento da triagem facilitando a tomada de decisões corretas no momento da transfusão e orientações voltadas a mulheres gestantes com sorologia positiva para aloanticorpos (PAHUJA et al., 2012; PROWONG et al., 2013).

\section{CONSIDERAÇÕES FINAIS}

A frequência e os tipos de anticorpos anti-eritrocitários irregulares variaram nos diferentes estudos e a frequência geral foi maior em doadores de sangue que apresentavam histórico de transfusão, assim como, em mulheres grávidas e multíparas devido a sensibilização que ocorre no período gestacional. Fatores naturais como idade, gênero e predisposição a infecções por verminoses podem influenciar na produção destes anticorpos irregulares.

No presente estudo foi possível evidenciar a escassez de registros na literatura acerca do tema abordado nessa pesquisa. A triagem pré-transfusional ainda necessita passar por aperfeiçoamentos, tais como padronização das técnicas mais sensíveis e com maior alcance na identificação de aloanticorpos, além que profissionais capacitados e competentes que atuem nesse setor, como meios para prevenir complicações como Doença Hemolítica Perinatal (DHPN) e reações hemolíticas no receptor. Portanto é relevante o desenvolvimento de mais estudos sobre os anticorpos irregulares em doadores de sangue para se obter dados mais amplos e com maior impacto epidemiológico e clínico, 
visto que pesquisas nacionais e internacionais sobre triagem de anticorpos irregulares em doadores de sangue são claramente deficientes.

\section{REFERÊNCIAS}

AGUIAR, Karina M. et al. Identificação de anticorpos irregulares no Hemocentro Regional de Monte Claros, MG. Revista Digital EFDeportes.com, Buenos Aires, ano. 17, n. 176, jan. 2013. Disponível em: <https:/ /www.efdeportes.com/efd176/ identificacao-de-anticorpos-irregulares-no-hemocentro.htm>. Acesso em: 07 mar 2018.

ALVES, Vitor M. et al. Pesquisa de aloimunização após transfusão de concentrados de hemácias em um estudo prospectivo. Revista Brasileira de Hematologia e Hemoterapia, Uberaba, v. 34, n. 3, p. 206-211, 2012.

BAIOCHI, Eduardo; NARDOZZA, Luciano M. M. Aloimunização. Revista Brasileira de Ginecologia e Obstetrícia, Rio de Janeiro, v. 31, n. 6, p. 311-319, 2009.

BRASIL. Ministério da Saúde. Imuno-hematologia laboratorial. 1. ed. Brasília, 2014.

BRASIL. Portaria de Consolidação n ${ }^{\circ}$ 5, de 28 de setembro de 2017. Diário Oficial [da] União, Poder Executivo, Brasília, DF, 28 fev. 2017. Seção 1, p. 926.

CONGRESSO NACIONAL DE INICIAÇÃO CIÊNTÍFICA, 13., 2013, Campinas. Anais do Conic-Semesp... Campinas, 2013, v.1.

ERIKSTEIN, B. S.; HAGEN, K. G.; HERVIG, T. RBC alloantibody prevalence and specificity in a Western Norwegian terttiary hospital. Transfusion Medicine, Bergen, v. 29, n. 3, p. 169-178, jan, 2018.

GARG, Neeraj; SHARMA, Tanya; SINGH, Bharat. Prevalence of irregular red blood cell antibodies among healthy blood donos in Delhi population. Transfusion and Apheresis Science, Delhi, v. 50, n. 3, p. 415-417, jun, 2014.

HELMAN, Ricardo; CANÇADO, Rodolfo D.; CRISTINA, Olivatto. Incidência de aloimunização eritrocitária em pacientes com doença falciforme: experiência de um centro em São Paulo. Hospital Israelita Albert Einstein, São Paulo, v. 9, n. 2, p. 160164, abr, 2011.

INTERNATIONAL SOCIETY OF BLOOD TRANSFUSION. Red Cell Immunogenetics and Blood Group Terminology: system. 2019. Disponível em: <https:/ /www.isbtweb. org/fileadmin/user_upload/Table_of_blood_group_systems_v6.0_6th_August_2019. pdf $>$. Acesso em: 20 ago 2020.

KEOKHAMPHOUI, Chirapha. et al. Red cell alloantibodies in Lao blood donos. Southeastt Asian Journal of Tropical Medicine na Public Haelth, Khon Kaen, v. 45, n. 1, p. 194-197, jan, 2014. 
LOKS, Melissa O. H. et al. Perfil De doadores de sangue que apresentaram reações adversas à doação. Revista Brasileira de Enfermagem, Brasília, v. 72, n. 1, p. 87-94 jan/fev. 2019.

MAKROO, Raj N. et al. Prevalence of irregular red cell antibody in healthy blood donos attending a tertiary care hospital in North India. Asian Journal of Transfusion Science, New Delhi, v. 12, n. 1, p. 17-20, 2018.

OLIVEIRA, Rodrigo C.; BRAGA, Jacqueline R. M. Frequência de anticorpos irregulares em serviço de transfusão de sangue em Salvador-BA, no período de 2009 a 2013. Revista Eletrônica Atualiza Saúde, Salvador, v. 2, n. 2, p. 51-57 jul/dez. 2015.

OLIVEIRA, Amanda Santos de. Frequência de anticorpos irregulares em pacientes politransfundidos em hemocentros no Brasil: uma revisão narrativa. 2016. 32 p. Trabalho de Conclusão de Curso (Graduação em Farmácia) - Departamento de Farmácia, Universidade Federal de Sergipe, São Cristóvão. 2016.

PAHUJA, Sangeeta. et al. Screennig off blood donos for erythrocyte alloantibodies. Journal Hematology, New Delhi, v. 17, n. 5, p. 302-305, sep, 2012.

PROMWONG, Charuporn. et al. Frequencies and specificities of red cell alloantibodies in the Southern Thai Population. Asian Journal of Transfusion Science, Songkla, v. 7, n. 1, p. 16-20, jan/jun, 2013.

RODRIGUES, Ana M. R. N. Sistemas sanguíneos e aloimunização eritrocitária: Importância Biológica e relevância clínica. 2015. 46 p. Trabalho de Conclusão de Curso (Especialização em Hematologia) - Academia de Ciência e Tecnologia, São José do Rio Preto. 2015.

RODRIGUES, Aline T. Aloimunização dos doadores de sangue como fonte de anti-soros e hemácias raras. 2016. 81p. Dissertação (Mestrado em Pesquisa e Desenvolvimento: Biotecnologia Médica) - Faculdade de Medicina, Universidade Estadual Paulista "Júlio de Mesquita Filho", Botucatu. 2016.

ROSA, Luiza S. Teste de antiglobulina humana indireto em gestantes aloimunizadas: uma revisão sistemática. 2018. 67 p. Trabalho de Conclusão de Curso (Graduação) Curso de nutrição, Universidade Federal de Santa Catarina, Florianópolis, 2016.

SILVA, José Manuel da. Fenotipagem eritrocitária em doadores de sangue no HEMOPI (Teresina - Picos) - PI e no Hemocentro Regional do Crato - CE. 2016. 71 f. Dissertação (Mestrado em Farmacologia) - Programa de pós-graduação em Farmacologia, Faculdade de Medicina, Universidade Federal do Ceará, Fortaleza, 2016.

VIZZON, Alexandre G.; SILVA, Flavia R. M. Teste da Antiglobulina Humana: uma revisão da literatura. Eletronic Journal of Pharmacy, v. 7, n. 3, p. 5-14, 2015. 